Gazi University
Journal of Science
http://dergipark.gov.tr/gujs

\title{
Unit Commitment Problem with Emission Cost Constraints by Using Genetic Algorithm
}

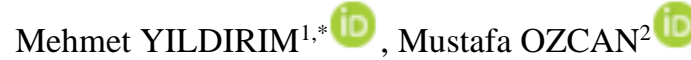 \\ ${ }^{1}$ Information Systems Engineering Department, Kocaeli University, 41380 Kocaeli, Turkey \\ ${ }^{2}$ Electricity and Energy Department, Kocaeli University, 41180, Kocaeli, Turkey
}

\section{Highlights}

- This paper presents a genetic algorithm solution to the unit commitment problem.

- A new formulation for cost-based unit commitment with emission costs is given.

- Test results for a 5-unit test system are reported.

- The amount of emission costs as a result of the operation of units are given.

- Emission costs constitute a large part of the operating cost.

\begin{tabular}{l} 
Article Info \\
\hline \\
Received: 25 May 2021 \\
Accepted: 23 Sep 2021 \\
Keywords \\
Economic dispatch \\
Emission costs \\
Genetic algorithms \\
Power system operation \\
and planning, \\
Unit commitment
\end{tabular}

\section{INTRODUCTION}

Flexibility has become a priority with the transition in power systems. It can be enhanced by research carried out in the areas of technology, production planning, plant operation and energy policies [1]. The solution of the unit commitment (UC) problem is among the flexibility enhancing procedures carried out as part of the operation of plants and production planning studies.

The growing importance of flexibility requires the development of plans which consider the power plants' operating parameters in generation expansion planning (GEP) studies [2]. The changes in the electricity markets and structure of power systems have also necessitated alterations in GEP parameters. The inclusion of short term planning studies in GEP has gained importance, and GEP studies which include UC have started to be carried out [3]. After the liberalization of the electricity market, the competition between electricity suppliers has increased. Consequently, suppliers have started to seek the most economical operational solutions for their power production plants in order to maximize their profits. The power system operating cost is reduced through the solution of UC problem. UC problem is a short-term electrical energy generation planning problem. To meet the demand with low operational cost satisfying the prevailing constraints, unit commitment consists of determining optimum operating combinations of generating units [4]. 
The UC is a large scale, combinatorial and non-linear optimization problem with constraints. UC is implemented as part of 24 or 48 -hour short term planning studies. The constraints of the UC problem change depending on each unit, such as start-up time, shut down time and ramping rates. In power systems, UC optimization is a difficult problem because it involves many constraints. Binary variables of 1 or 0 stand for the status of the generating units, on/off, while continuous ones are used to stand for unit power. As the number of variables rises, the number of their combinations rises exponentially, making the UC problem large-scale.

A large number of optimization methods have been used to solve the UC problem. Besides the use of various deterministic and heuristic methods separately, hybrid methods which employ these simultaneously have been employed [5]. Some of the deterministic methods that have been used are branch \& bound algorithm, mixed integer programming and priority list. The most frequently employed heuristic algorithm is the genetic algorithm (GA) [6,7]. Other than GA, particle swarm optimization [8], ant colony optimization [9], simulated annealing, artificial neural networks, expert systems, evolutionary programming and tabu search algorithms are among heuristics used in UC.

In this study, by using GA, a short-term thermal UC problem was solved. Considering the environmental concerns on the world agenda, emission costs of generating units have been included in the objective function. Total operating cost (objective function) which includes start-up, shut down, fuel and emission costs has been minimized by satisfying prevailing constraints. For a 24-hour planning period, the proposed algorithm was tested by using a five thermal unit test system and the optimum generating unit schedules that meet the constraints for each hour. The paper is organized as follows: Test data and the mathematical model of the study are given in the second section. In section three, the results obtained by the solution of the problem via GA on a test system are given. In the last section, the conclusions of the study are stated.

\section{PROBLEM FORMULATION}

\subsection{Notation}

The notations used in the paper are given in Table 1.

Table 1. Notations

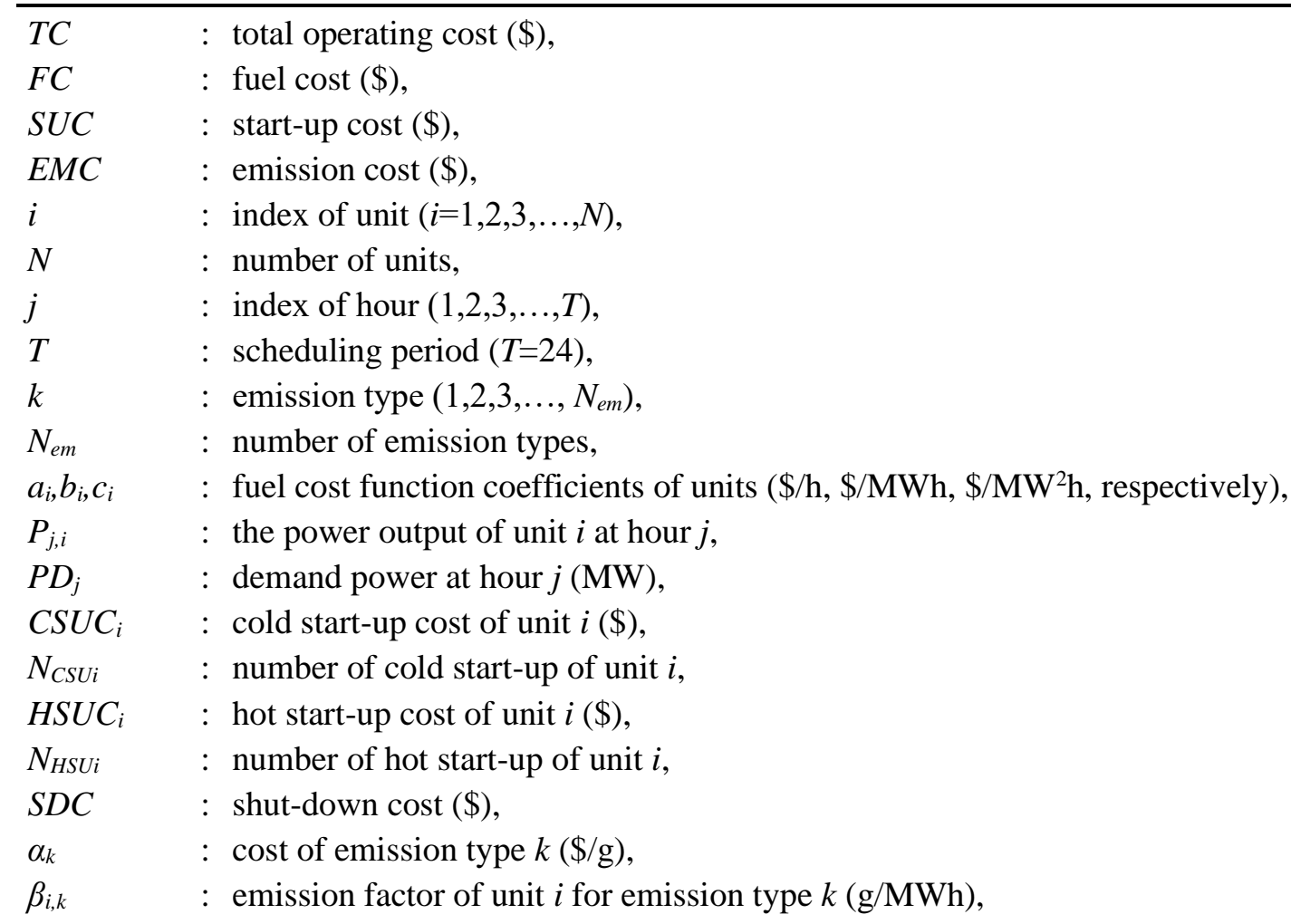




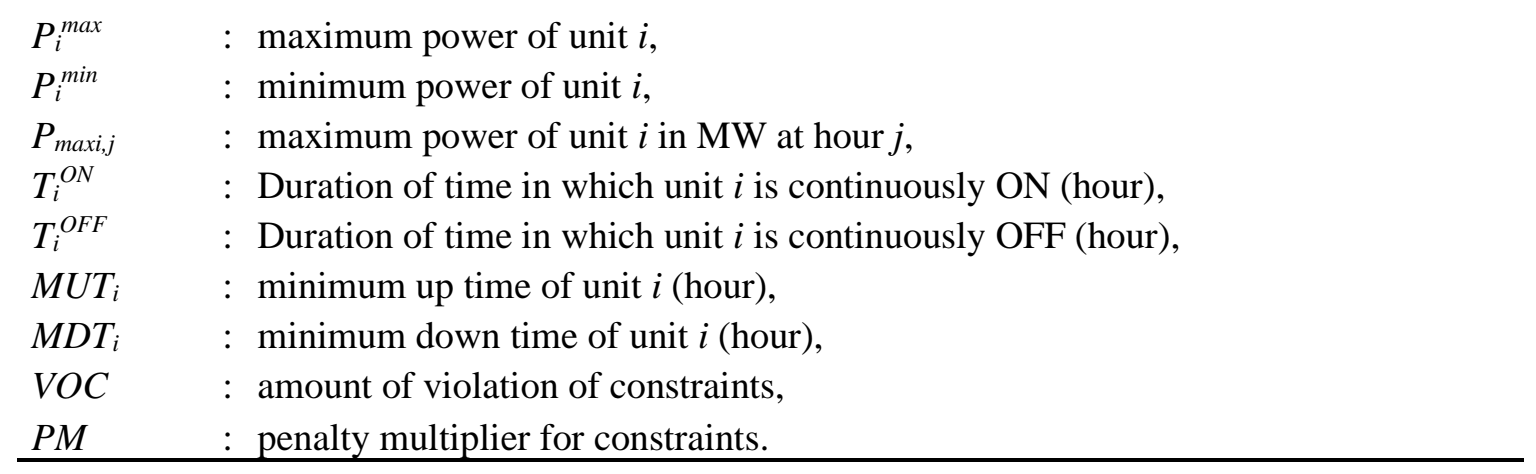

\subsection{Objective Function}

To determine an optimum schedule of generating units, while respecting all the prevailing constraints, a solution of a UC problem is aimed with a minimum operating cost. Total operation cost consists of startup, fuel and emission costs. Therefore, these cost values are the economic parameters to be considered in the UC problem solution. Total operating cost is the sum of the start-up costs, emission costs and fuel costs over the scheduling period. Accordingly, the UC's objective function is given in Equation (1) [10,11]

$T C=F C+S U C+E M C+$ Penalty

$T C=\left[\sum_{j=1}^{T} \sum_{i=1}^{N}\left(a_{i}+b_{i} P_{j, i}+c_{i} P_{j, i}{ }^{2}\right)\right]+\left[\sum_{i=1}^{N} N_{C S U_{i}} * C S U C_{i}+N_{H S U_{i}} * H S U C_{i}\right]+\left[\sum_{j=1}^{T} \sum_{i=1}^{N} \sum_{k=1}^{N_{e m}} \alpha_{k} \cdot \beta_{i, k} \cdot P_{j, i}\right]$

Penalty $=P M * V O C$.

Fuel cost: Thermal generating units' fuel cost function is given in Equation (3)

$F C=a_{i}+b_{i} \cdot P_{j, i}+c_{i} \cdot P_{j, i}{ }^{2}$

Start-up cost: The start-up cost occurs when the unit is started. It can be a cold or hot start-up cost. Depending on the hours the unit was out of service before it started up, the start-up cost changes. The startup cost is considered cold start-up cost, if the period the unit was out of service is longer than the cold startup time, otherwise the start-up cost is hot start-up cost [12]. Shut-down costs occur when units in service are taken out of service. Since the cost of shutting down units is very low, shut-down costs in this study were taken as zero.

Emission cost: Assuming that the emission cost which occurs as a result of $\mathrm{CO}_{2}, \mathrm{SO}_{2}$ and $\mathrm{NOx}$ emisssions, due to the burning of fossil fuels is a linear function of net power, it is calculated by Equation (4) [10]

$E M C=\sum_{i=1}^{N} \sum_{k=1}^{N_{e m}} \alpha_{k} \cdot \beta_{i, k} \cdot P_{j, i}$.

Emission costs for the units included in this study are: $0.00001 \$ / \mathrm{g}$ for $\mathrm{CO}_{2}, 0.00000007 \$ / \mathrm{g}$ for $\mathrm{SO}_{2}$ and $0.000002 \$ / g$ for $\mathrm{NO}_{\mathrm{X}}[13-15]$

\subsection{Constraints}

The constraints in the UC problem consist of unit constraints and system constraints. Spinning reserve and load balance constraints are system constraints. The total power supplied by the units has to meet the power demand and should be able and ready to provide a predetermined amount of power in case a loss of supply occurs. Unit constraints result from physical constraints of generating units (generators). It is not possible to put generators into service at once or leave them out of service before a certain amount of time passes. 
The power to be obtained from generators should remain within production limits and the power fluctuations allowed by the specific type of generator should not be exceeded [16].

System constraints: System constraints consist of spinning reserve and load balance constraints.

Load Balance Constraint: The power generated by the units for each point $t$ in time should be equal to or more than the power demand. System losses are included in the power demand. Power demand is calculated by Equation (5)

$\sum_{i=1}^{N} P_{j, i}-P D_{j} \geq 0 \quad ; \forall j$

Spinning reserve constraint: Reserve power refers to the difference between the production capacity of the system operator and the consumer demand. The basic aim in all reserve types is to maintain the loadproduction balance at different time intervals. The most basic measure that shows the sufficiency of the capacity of the generating unit is the operating reserve. Operating reserve consists of various reserve power constituents. Spinning reserve is the operating reserve which can start operating in synchrony with the system within 10 minutes in response to changing demand [17].

Spinning reserve is one of the most important resources used by system operators in response to any shortfall in generation and sudden unforeseen load changes. A certain part of the generation capacity is retained by electric power system operators as reserve power. As a result, the system can run in a stable manner without load shedding.

Unit constraints: Unit constraints include ramping constraints of the units, the units' minimum up time and the units' minimum down time.

Ramping constraints of units: The amount of each unit's generatedpower should be in the range of maximum and minimum allowable power output of it. This is expressed by Equation (6)

$P_{i}^{\min } \leq P_{j, i} \leq P_{i}^{\max }$

Unit's minimum up time: The minimum period of time the generators should be up is calculated by Equation (7)

$\sum_{j=1}^{T}\left|T_{i, j}{ }^{N N}-M U T_{i}\right| \gg 0$.

Unit's minumum down time: The minimum period of time the generators should remain down is calculated by Equation (8)

$\sum_{j=1}^{T}\left|T_{i, j}^{O F F}-M D T_{i}\right| \gg 0$.

The data for the units used in this study are shown in Table $2[6,11,18]$.

Table 2. Data for the test system with 5-units [6,11,18]

\begin{tabular}{lrrrrr}
\hline & \multicolumn{1}{c}{ Unit 1 } & \multicolumn{1}{c}{ Unit 2 } & Unit 3 & Unit 4 & Unit 5 \\
\hline Type of unit & Lignite-fired & Hard coal-fired & Hard coal-fired & CCGT & CCGT \\
$\mathbf{C O}_{2}$ emission factor(g/MWh) & 1060000 & 770000 & 770000 & 400000 & 400000 \\
$\mathbf{S O}_{2}$ emission factor (g/MWh) & 430 & 330 & 330 & 0 & 0 \\
NOX emission factor (g/MWh) & 790 & 500 & 500 & 100 & 100 \\
Pmax (MW) & 455 & 130 & 130 & 80 & 55 \\
Pmin (MW) & 150 & 20 & 20 & 20 & 10 \\
a (\$/h) & 1000 & 700 & 680 & 370 & 660
\end{tabular}


b (\$/MWh)
c (\$/MW^2h)

Minumum up time (h)

Minimum down time (h)

Hot start-up time cost (\$)

Cold start-up cost (\$)

Cold start-up time (h)

Initial state (h)

16.19
0.00048
8
8
4,500
9,000
5
8

16.60

0.002

5

5

550

1,100

4

8

\begin{tabular}{rrr}
16.50 & 22.26 & 25.92 \\
0.00211 & 0.00712 & 0.00413 \\
5 & 3 & 1 \\
5 & 3 & 1 \\
560 & 170 & 30 \\
1,120 & 340 & 60 \\
4 & 2 & 2 \\
-5 & -3 & -1 \\
\hline
\end{tabular}

At the beginning of the scheduling period, generating units' initial states were considered. In Table 2, the expression "+" indicates the period the unit is committed, and the expression "-. indicates the period it is not committed. In Table 3, hourly load demand values of the test system are indicated.

Table 3. Load demand for 24-hours [6,11]

\begin{tabular}{lrlr}
\hline Hour (h) & $\begin{array}{c}\text { Demand } \\
(\mathbf{M W})\end{array}$ & Hour (h) & $\begin{array}{c}\text { Demand } \\
(\mathbf{M W})\end{array}$ \\
\hline 1 & 400 & 13 & 650 \\
2 & 450 & 14 & 620 \\
3 & 480 & 15 & 600 \\
4 & 500 & 16 & 550 \\
5 & 530 & 17 & 500 \\
6 & 550 & 18 & 550 \\
7 & 580 & 19 & 600 \\
8 & 600 & 20 & 650 \\
9 & 620 & 21 & 600 \\
10 & 650 & 22 & 550 \\
11 & 680 & 23 & 500 \\
12 & 700 & 24 & 450 \\
\hline
\end{tabular}

\section{TEST RESULTS}

A GA has been used in this study to solve the UC problem of a 5-unit $(\mathrm{N}=5)$ test system to minimize total operating cost in daily scheduling $(\mathrm{T}=24)$. Binary encoding and single point crossover was employed. Roulette wheel selection was the preferred selection method and rank-based fitness assignment was applied. The GA chromosome structure used in the study is shown in Figure 1.

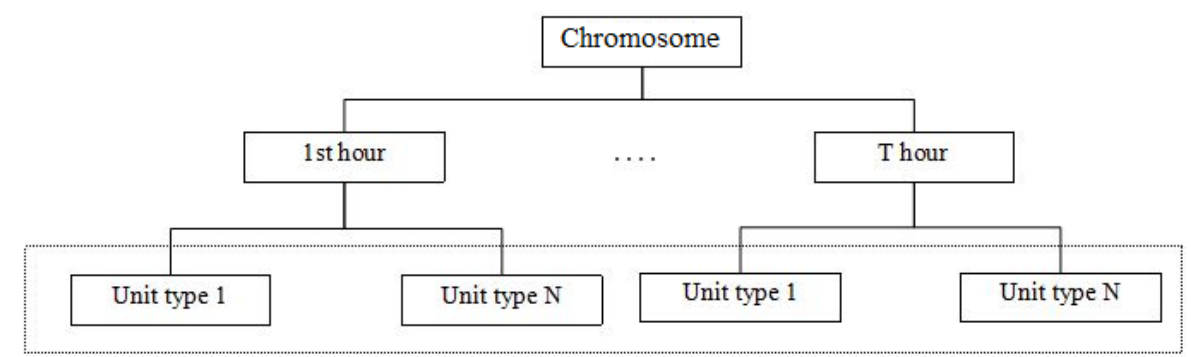

Figure 1. A chromosome structure used in the GA

In order to identify the optimum GA parameters, the algorithm was run separately for different mutation rates and population sizes. Each time, the convergence of the algorithm to the lowest objective function was observed. In order to determine the mutation rate's effect; mutation rates of $.002, .005, .01$ and .05 were evaluated. The algorithm was run separately for population sizes of 50, 100 and 200 chromosomes to 
determine the optimum parameters. The lowest objective function value was obtained when the population size was 100 and the mutation rate was .002 . Therefore, these values were used in the GA to solve the problem. The GA was run for 10,000 generations with .002 mutation rate, crossover rate of 1 and population size of 100, and the optimum value of the objective function was obtained. The convergence curve of the objective function is shown in Figure 2.

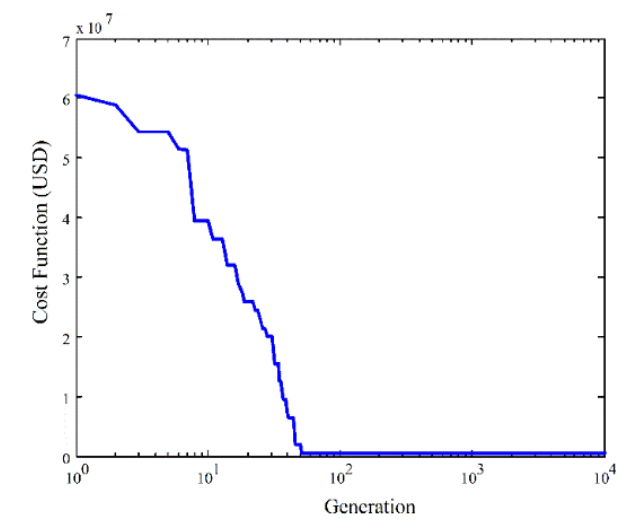

Figure 2. Objective function convergence curve

The solution of the UC problem for a 5-unit test system in a 24 -hour scheduling period gives $\$ 430330$ as the lowest cost value.

Within the scheduling period, for each hour, the power generated by the units has to be provided by a certain spinning reserve in order to satisfy the demanded power. Power demanded is met by a certain amount of spinning reserve during each hour of the scheduling period. The schedule is achieved by means of the flowchart given in Figure 3.

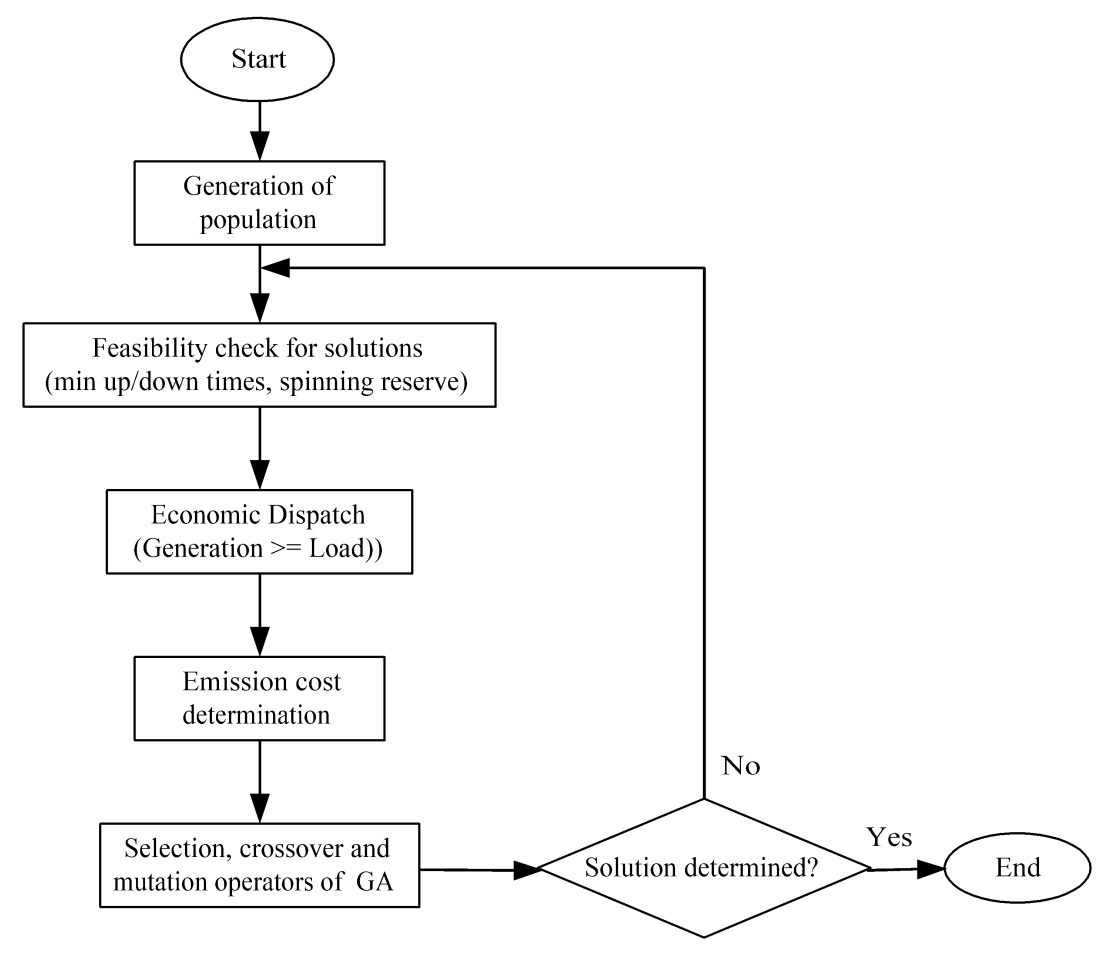

Figure 3. Flowchart of the problem solution

According to the UC problem solution, generating units' optimal schedule is given in Figure 4. 


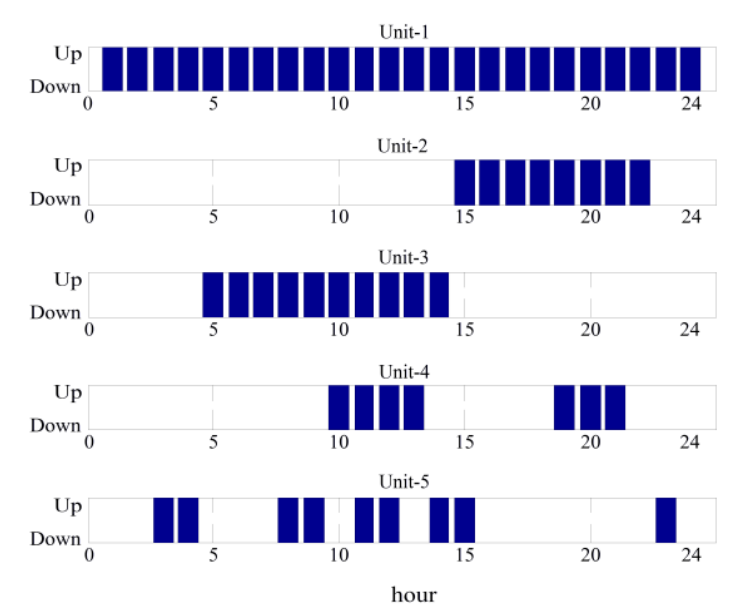

Figure 4. Generating units' optimal schedule

Unit 1 remains committed throughout the planning period, as seen in Figure 4. It is the unit with the highest cost value with a total cost of $\$ 318946.7$. Unit 2 was only in service once for a duration of 7 hours between 15:00 - 22:00, and has a cost of $\$ 32245.46$. The cost value of Unit 3 was $\$ 39738.33$ and it was committed for a duration of 10 hours between 5:00 -14:00. Unit 4 went into service twice between 10:00 - 13:00 and 19:00 - 21:00, for 4 hours and 3 hours, respectively. It has a cost value of $\$ 18294.91$. Unit 5 was committed for 5 times and has a cost value of $\$ 21102.99$.

Considering the initial states and cold start-up durations of the units, cold and hot start-up costs were obtained. Based on these and the number of hot and cold start-ups for the units shown in Figure 4, the startup costs were calculated as shown in Table 4.

Table 4. Cold start-up \& hot start-up data

\begin{tabular}{lrrrrr}
\hline & $\begin{array}{c}\text { Number } \\
\text { of cold } \\
\text { start- up }\end{array}$ & $\begin{array}{c}\text { Number } \\
\text { of hot } \\
\text { start-up }\end{array}$ & $\begin{array}{c}\text { Cold } \\
\text { start-up } \\
\text { cost (\$) }\end{array}$ & $\begin{array}{c}\text { Hot } \\
\text { start- } \\
\text { up cost } \\
\text { (\$) }\end{array}$ & $\begin{array}{c}\text { Total } \\
\text { start- } \\
\text { up cost } \\
\text { (\$) }\end{array}$ \\
\hline Unit-1 & 0 & 0 & 0 & 0 & 0 \\
Unit-2 & 1 & 0 & 1100 & 0 & 1100 \\
Unit-3 & 1 & 0 & 1120 & 0 & 1120 \\
Unit-4 & 2 & 0 & 680 & 0 & 680 \\
Unit-5 & 3 & 2 & 180 & 60 & 240 \\
Total & 7 & 2 & 3080 & 60 & 3140 \\
\hline
\end{tabular}

The values of the cost components, together with spinning reserve and UC combinations within the scheduling period are given in Table 5 for each hour. 
Table 5. Hourly cost components, spinning reserve and UC combinations

\begin{tabular}{lrrrrrrrrr}
\hline Hour & $\begin{array}{c}\text { Start up cost } \\
\text { (US \$) }\end{array}$ & $\begin{array}{c}\text { Fuel cost } \\
\text { (US \$) }\end{array}$ & $\begin{array}{c}\text { Emission } \\
\text { cost (US \$) }\end{array}$ & $\begin{array}{c}\text { Spinning } \\
\text { reserve } \\
\text { (MW) }\end{array}$ & $\begin{array}{c}\text { Generation schedule } \\
\text { (on / off) }\end{array}$ \\
\hline 1 & 0 & 8465,8 & 4823,7 & 55 & 1 & 0 & 0 & 0 & 0 \\
2 & 0 & 8465,8 & 4827,7 & 5 & 1 & 0 & 0 & 0 & 0 \\
3 & 60 & 10563,9 & 5043,7 & 30 & 1 & 0 & 0 & 0 & 1 \\
4 & 0 & 10563,9 & 5043,7 & 10 & 1 & 0 & 0 & 0 & 1 \\
5 & 1120 & 11326,5 & 5824,8 & 55 & 1 & 0 & 1 & 0 & 0 \\
6 & 0 & 11326,5 & 5824,8 & 35 & 1 & 0 & 1 & 0 & 0 \\
7 & 0 & 11326,5 & 5824,8 & 5 & 1 & 0 & 1 & 0 & 0 \\
8 & 60 & 13424,6 & 6044,8 & 40 & 1 & 0 & 1 & 0 & 1 \\
9 & 0 & 13424,6 & 6044,8 & 20 & 1 & 0 & 1 & 0 & 1 \\
10 & 340 & 13522,9 & 6144,8 & 15 & 1 & 0 & 1 & 1 & 0 \\
11 & 30 & 15621 & 6364,8 & 40 & 1 & 0 & 1 & 1 & 1 \\
12 & 0 & 15621 & 6364,8 & 20 & 1 & 0 & 1 & 1 & 1 \\
13 & 0 & 13522,9 & 6144,8 & 15 & 1 & 0 & 1 & 1 & 0 \\
14 & 30 & 13424,6 & 6044,8 & 20 & 1 & 0 & 1 & 0 & 1 \\
15 & 1100 & 13455,7 & 6044,8 & 40 & 1 & 1 & 0 & 0 & 1 \\
16 & 0 & 11357,6 & 5824,8 & 35 & 1 & 1 & 0 & 0 & 0 \\
17 & 0 & 11357,6 & 5824,8 & 85 & 1 & 1 & 0 & 0 & 0 \\
18 & 0 & 11357,6 & 5824,8 & 35 & 1 & 1 & 0 & 0 & 0 \\
19 & 340 & 13554 & 6144,8 & 65 & 1 & 1 & 0 & 1 & 0 \\
20 & 0 & 13554 & 6144,8 & 15 & 1 & 1 & 0 & 1 & 0 \\
21 & 0 & 13554 & 6144,8 & 65 & 1 & 1 & 0 & 1 & 0 \\
22 & 0 & 11357,6 & 5824,8 & 35 & 1 & 1 & 0 & 0 & 0 \\
23 & 60 & 10563,9 & 5043,7 & 10 & 1 & 0 & 0 & 0 & 1 \\
24 & 0 & 8465,8 & 4823,7 & 5 & 1 & 0 & 0 & 0 & 0 \\
Total & 3140 & 289178,3 & 138012,6 & 755 & & & & & \\
\hline & & & & & & & & \\
19 & & & & & & & & &
\end{tabular}

Fuel, emission and start-up costs which are components of the total operating cost are given for each unit for the 24-hour scheduling period in Figure 5.

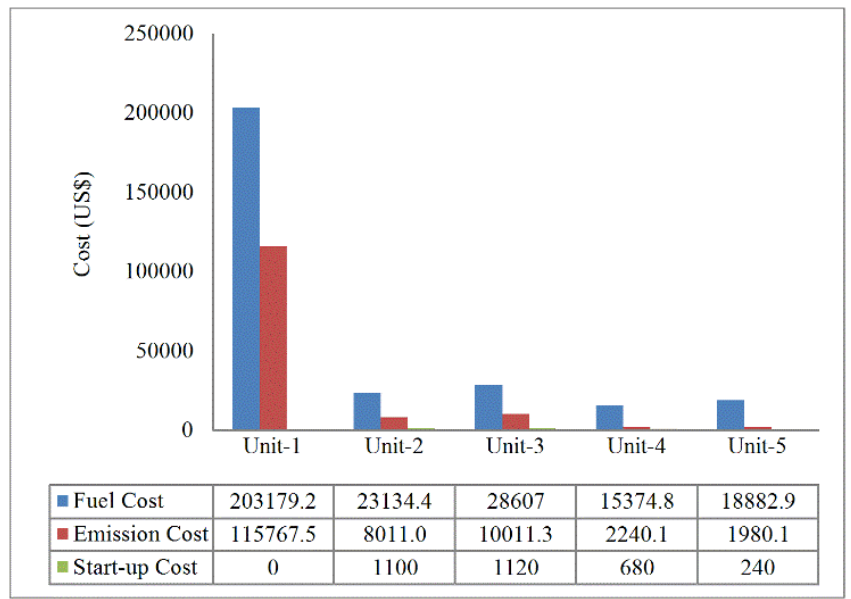

Figure 5. Cost values for the units

The emission costs according to the unit types that occur as a result of the operation of units are given in Figure 6. 


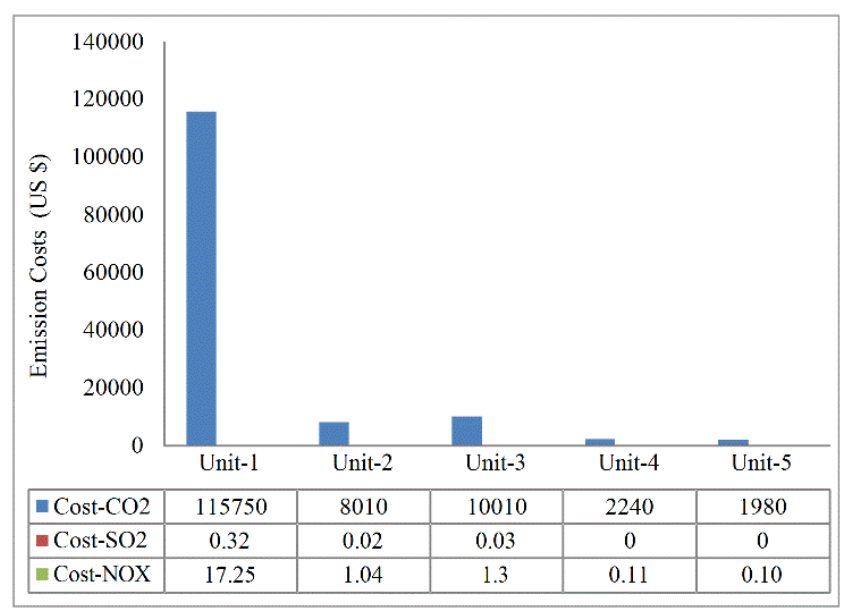

Figure 6. Costs according to emission types

Unit1 has the highest $\mathrm{CO}_{2}$ emission value, because it runs on lignite coal. Units 2 and 3 run on hard coal which has the second highest emission value after lignite coal. However, since they operate only once each, their emission values are below Unit 1 .

The total operating cost for a 24 -hour scheduling period is $\$ 430330,67 \%$ of which comes from fuel cost. Start-up, emission and fuel costs are calculated as \$3140 (1\%), \$138010 (32\%) and \$289178 (67\%), respectively. Total start-up cost comprises of cold and hot start-up costs. Cold and hot start-up costs are found to be $\$ 60$ and $\$ 3080$, respectively.

\section{CONCLUSION}

The UC problem for a 24 hour scheduling period and with a 5-unit test system was solved using GA. The objective function value, which consists of start-up, fuel and emission costs, was minimized while satisfying all the constraints specific to the problem. Taking into consideration the importance of climate change in the global agenda, emission costs were also included in the objective function.

During the 24 hour scheduling period, 13360 MW of demand power was met by a designated spinning reserve. Total spinning reserve value during the scheduling period was $755 \mathrm{MW}$ and this corresponds to $5.65 \%$ of the total demand.

As a result of the solution of 5-unit UC test problem, lowest cost value was found to be $\$ 430330$.

$32 \%$ of the total operating cost came from emission costs. Almost all of the total emission cost, estimated as $\$ 137990$, was due to $\mathrm{CO}_{2}$ emissions. The total of $\mathrm{CO}_{2}$ emissions from Unit 1 , Unit 2 and Unit 3, which run on hard coal and lignite coal, comprise approximately $97 \%$ of total $\mathrm{CO}_{2}$ emissions. Since Unit 4 and Unit 5 are CCGT plants, they do not have $\mathrm{SO}_{2}$ emissions and their $\mathrm{NO}_{\mathrm{x}}$ emission is less compared to units which run on hard coal and lignite coal.

\section{CONFLICTS OF INTEREST}

No conflict of interest was declared by the authors.

\section{REFERENCES}

[1] International Energy Agency, "Status of power system transformation 2019- Power system flexibility”, Paris, France, (2019).

[2] Schwele, A., Kazempour, J., Pinson, P., "Do unit commitment constraints affect generation expansion planning? A scalable stochastic model”, Energy Systems, 11: 247-282, (2020). 
[3] Koltsaklis, N.E., Dagoumas, A.S., "State-of-the-art generation expansion planning: A review", Applied Energy, 230: 563-589, (2018).

[4] Jeong, Y-W., Park, J-B., Shin, J-R., Kwang, Y.L., "A thermal unit commitment approach using an improved quantum evolutionary algorithm", Electric Power Components and Systems, 37(7): 770786, (2009).

[5] Saravanan, B., Das, S., S1kr1, S., Kotharı, D.P., "A solution to the unit commitment problem-a review", Frontiers in Energy, 7(2): 223-236, (2013).

[6] Kazarlis, S.A., Bakirtzis, A.G., Petridis, V., "A genetic algorithm solution to the unit commitment problem”, IEEE Transactions on Power Systems, 11(1): 83-92, (1996).

[7] Uyar, A.Ş., Türkay, B.,"Evolutionary algorithms for the unit commitment problem”, Turkish Journal of Electrical Engineering and Computer Science, 16(3): 239-255, (2008).

[8] Najafi, A., Farshad, M., Falaghi, H., "A new heuristic method to solve unit commitment by using a time-variant acceleration coefficients particle swarm optimization algorithm", Turkish Journal of Electrical Engineering \& Computer Sciences, 23: 354-369, (2015).

[9] Simon, S.P., Padhy, N.P., Anand, R.S., "An ant colony system approach for unit commitment problem", International Journal of Electrical Power \& Energy Systems, 28(5): 315-323 (2006).

[10] Nemati, M., Braun, M., Tenbohlen S., "Optimization of unit commitment and economic dispatch in microgrids based on genetic algorithm and mixed integer linear programming", Applied Energy, 210: 944-963, (2018).

[11] Alkanoğlu, U., "Short term unit commitment by using genetic algorithms", MSc Thesis, Kocaeli University, Kocaeli, Turkey, (2007).

[12] Gil, E., Bustos, J., Rudnick, H., "Short-term hydrothermal generation scheduling model using a genetic algorithm", IEEE Transactions on Power Systems, 18(4): 1256-1264, (2003).

[13] “Average Spot Price for Sulfur Dioxide ( $\left.\mathrm{SO}_{2}\right)$ Emissions Allowances- 2019”, United States Environmental Protection Agency, (2020). https://www.epa.gov/airmarkets/2019-so2-allowanceauction, (2019). Access date:13.09.2020

[14] "State and Trends of Carbon Pricing 2019", International Bank for Reconstruction and Development, Washinghton DC, USA, (2019). https://openknowledge.worldbank.org/handle/10986/31755. Access date: 14.09 .2020

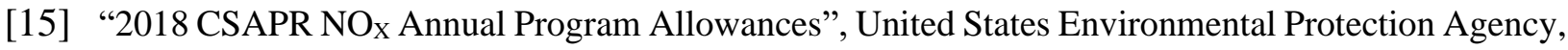
018 Power Sector Programs - Progress Report, (2020). https://www3.epa.gov/airmarkets/progress/reports/index.html. Access date: 13.09.2020

[16] Sapmaz, M.E., "A genetic algorithms solution to the unit commitment problem", MSc, Istanbul Technical University, Istanbul, Turkey, (2004).

[17] "Balancing and Frequency Control Basics", North American Electric Reliability Corporation, Princeton, USA, https://www.nerc.com/docs/oc/rs/NERC\%20Balancing\%20and\%20Frequency\%20Control\%20040 520111.pdf. Access date: 13.09.2020 
[18] "Lifecycle Emissions from Power Generating Technologies, The Cost of Power Generation- The Current and Future Competitiveness of Renewable And Traditional Technologies", Business Insights, (2010). 